\title{
Poly(isobornyl methacrylate-co-3-( $t$-butoxycarbonyl)-1-vinyl-2-caprolactam) for an Environmentally Stable Chemically Amplified Resist
}

\author{
Jin-Baek Kıм, ${ }^{\dagger}$ Jae-Hak CHoI, Hyunwoo KIM, Young-Gil Kwon* \\ and Min-Ho JUNG
Department of Advanced Materials Engineering, Korea Advanced Institute of Science and Technology, P. O. Box 201, Cheongryang, Seoul 130 650, Korea
* Department of Chemistry, Korea Advanced Institute of Science and Technology,
373-1, Kusong-dong, Yusong-gu, Taejon 305-701, Korea

(Received November 10, 1998)

\begin{abstract}
Poly(isobornyl methacrylate-co-3-(t-butoxycarbonyl)-1-vinyl-2-caprolactam) was synthesized and evaluated as a new matrix polymer for a deep UV resist. The polymer has low absorbance at $248 \mathrm{~nm}$ (absorbance: $0.014-0.034 \mu \mathrm{m}^{-1}$ ) and good thermal stability up to $250^{\circ} \mathrm{C}$. The diffusion lengths of photo-generated acid in the resist films were studied for various fractions of the basic monomer in the copolymers. The results show that the copolymer with a basic monomer can control acid diffusion. $0.25 \mu \mathrm{m}$ line/space patterns were obtained for this resist system using a $\mathrm{KrF}$ excimer laser stepper. The pattern profile was not deformed and T-top was not observed after $2 \mathrm{~h}$ post-exposure delay. The polymer has etch resistance comparable to the novolac resist under $\mathrm{CHF}_{3}$ plasma.

KEY WORDS Chemically Amplified Resist / Post-Exposure Delay Stability / Acid Diffusion

1-Vinyl-2-Caprolactam
\end{abstract}

Most chemically amplified resists (CARs) are extremely susceptible to contamination by trace amounts of airborne basic substances such as 1,1,1,3,3,3-hexamethyldisilazane (HMDS) and 1-methyl-2-pyrrolidinone. The basic contaminants can neutralize the surface acid in the exposed area of the photoresist during postexposure delay (PED) between the exposure and the post-exposure bake (PEB) steps, and cause T-shaped profiles and enlarged critical dimensions. ${ }^{1.2}$ Several methods have been proposed to solve this problem, such as purification of the wafer-enclosing atmosphere by activated carbon filtration, ${ }^{3}$ application of a protective top overcoat, ${ }^{4}$ reduction of resist film free volume by annealing, ${ }^{5}$ reduction of activation energy of deprotection, ${ }^{6.7}$ and incorporation of a stabilizing additive in resist formulation. ${ }^{8}{ }^{8}$ However, there still exists a serious need for designing a chemically amplified resist which is insensitive to airborne contamination.

Recently, we developed new CARs using basic polymers such as poly(3-( $t$-butoxycarbonyl)-1-vinyl-2pyrrolidinone and poly(3-( $t$-butoxycarbonyl)-1-vinyl-2caprolactam. ${ }^{10-12}$ These resists have been found to give improved resolution and PED stability. Methacrylate polymers containing alicyclic hydrocarbons such as adamantyl, ${ }^{13,14}$ menthyl, ${ }^{15}$ isobornyl, ${ }^{16}$ and tricyclodecanyl ${ }^{17.18}$ groups have been proposed as matrix resins for their high transparency in deep UV region and good dry-etching resistance. In this study, we prepared copolymers of an alicyclic monomer and a basic monomer in order to improve both dry-etching resistance and PED stability. The physical properties and lithographic performance were evaluated as novel deep UV photoresists.

\section{EXPERIMENTAL}

\section{Materials}

2,2'-Azobisisobutyronitrile (AIBN) purchased from Tokyo Chemical Industry was purified by recrystallization in diethyl ether. Isobornyl methacrylate (IBMA) purchased from Aldrich chemical company was distilled under reduced pressure. 3-(t-Butoxycarbonyl)-1-vinyl-2caprolactam (BCVC) as a basic monomer was synthesized as described in our previous publications. ${ }^{10-12}$ Triphenylsulfonium hexafluoroantimonate (TPSHFA) and triphenylsulfonium triflate (TPSTf) as a photoacid generator (PAG) were synthesized according to the literature. $^{19}$

\section{Measurements}

Infrared spectra were obtained on a Bio-Rad FTS165 spectrometer. UV spectra were recorded as spincoated films on quartz plates with a Hewlett-Packard Model 8453 spectrophotometer. Number-average molecular weight and molecular weight distribution were determined in tetrahydrofuran by a Waters GPC-150C calibrated with polystyrene standards. Elemental analyses of polymers were done with an Elemental Analyzer (Carlo Erba Co.). Thermogravimetric analysis (TGA) and differential scanning calorimetry (DSC) data were obtained on a Perkin-Elmer TA 7 series system at a heating rate of $10^{\circ} \mathrm{C} \mathrm{min}^{-1}$ and $20^{\circ} \mathrm{C} \mathrm{min}^{-1}$, respectively. Contact exposures were done on an Oriel co. exposure system with a filter transmitting light between 220 $260 \mathrm{~nm}$. Excimer laser exposures were performed at $248 \mathrm{~nm}$ with a Nikon NSR $2005 \mathrm{KrF}$ excimer laser stepper with 0.55 NA. Resist development was done by immersion in a developer solution. Etch rates were measured with a Plasma Technology RIE-80 system.

Free Radical Copolymerization of IBMA and BCVC A series of polymers was synthesized with various 
Table I. Polymerization of IBMA and BCVC

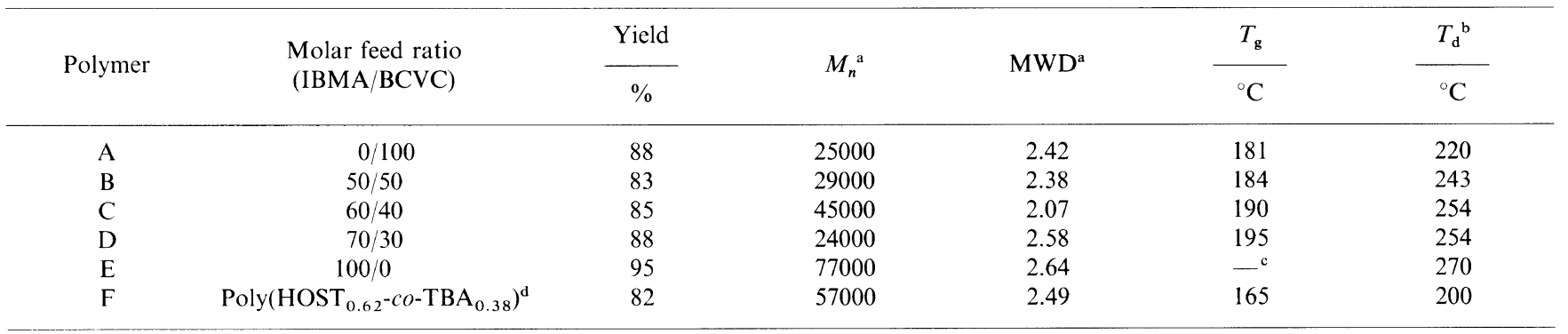

${ }^{a}$ Molecular weights and molecular weight distribution determined by GPC with polystyrene standards. ${ }^{\mathrm{b}}$ Decomposition temperature determined as the onset temperature instrumentally. ${ }^{\mathrm{c}} T_{q}$ not obtained below decomposition temperature. ${ }^{\mathrm{d}}$ Copolymer composition calculated from peak integration of aromatic and aliphatic protons in the ${ }^{1} \mathrm{H}$ NMR spectra of the copolymer.

monomer feed ratios using $1 \mathrm{~mol} \%$ of $\mathrm{AIBN}$ as an initiator in 1,4-dioxane solution at $60^{\circ} \mathrm{C}$ under vacuum in a sealed ampoule for $24 \mathrm{~h}$. The polymers were precipitated three times into a large amount of petroleum ether. The resultant precipitate was filtered and dried under reduced pressure.

\section{Measurement of the Acid Diffusion Length 20,21}

Copolymer solution in cyclohexanone without the PAG was spin-coated onto silicon wafers and baked on a hot plate at $100^{\circ} \mathrm{C}$ for $2 \mathrm{~min}$. A mixture solution of $1.0 \mathrm{~g}$ of poly(vinyl alcohol) and $0.07 \mathrm{~g}$ of TPSTf in $18.0 \mathrm{~g}$ of water was spin-coated on top of the copolymer films and baked again at $100^{\circ} \mathrm{C}$ for $2 \mathrm{~min}$. To generate acid in the poly(vinyl alcohol) top layer, the films were exposed to deep-UV light at a dose of $100 \mathrm{~mJ} \mathrm{~cm}^{-2}$. The films were stored in air for various times. During this delay, the acid diffused into the bottom copolymer layer. The top layer was removed by washing with pure water. The remaining copolymer bottom layer was baked at $110^{\circ} \mathrm{C}$ for $2 \mathrm{~min}$. The copolymer film was developed in 2.38 wt $\%$ tetramethylammonium hydroxide (TMAH) aqueous solution for $2 \mathrm{~min}$. The depth difference between exposed and unexposed areas in the copolymer film was measured with an Alpha-step 500 surface profiler (Tencor Instrument).

\section{Lithographic Evaluation}

A resist solution was made by dissolving $10 \mathrm{~g}$ of polymer and $0.7 \mathrm{~g}$ of TPSHFA as a PAG in $80 \mathrm{~g}$ of cyclohexanone. This solution was filtered through a $0.1 \mu \mathrm{m}$ filter and spin-coated onto HMDS-primed silicon wafers and baked at $120^{\circ} \mathrm{C}$ for $2 \mathrm{~min}$ on a hot plate to form about $1.0 \mu \mathrm{m}$ thick films. Exposure was carried out on a $\mathrm{KrF}$ excimer laser stepper (0.55 NA). For PED stability test, the exposed wafer was stored for $2 \mathrm{~h}$ before $P E B$ in a cluster with chemical filter in which ammonia concentration was $5 \mathrm{ppb}$. The exposed films were baked at $140 \mathrm{C}$ for $2 \mathrm{~min}$ and developed in $2.38 \mathrm{wt} \% \mathrm{TMAH}$ aqueous solution. Etch studies were done using a parallel plate rf reactive ion etcher. Typical process conditions were $100 \mathrm{~m}$ Torr pressure and $100 \mathrm{sccm}$ gas flow at $200 \mathrm{~mW}$ rf power. Source gas, $\mathrm{CHF}_{3}$, was used to determine etch rates relative to a Hoechst AZ 1512 novolac resist.

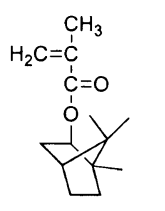

IBMA

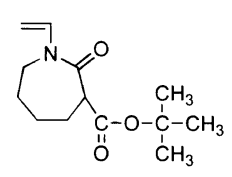

$\mathrm{BCVC}$

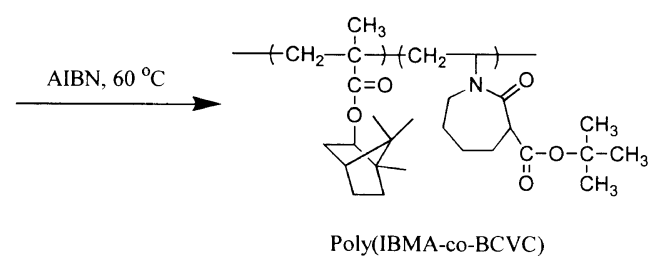

Figure 1. Polymerization scheme.

Table II. Results of elemental analysis

\begin{tabular}{|c|c|c|}
\hline \multirow{2}{*}{ Polymer } & $\mathrm{N}$ content $\mathrm{t}^{\mathrm{a}}$ & BCVC content $^{\mathrm{b}}$ \\
\hline & $\%$ & $\mathrm{~mol} \%$ \\
\hline B & 2.49 & 41.42 \\
\hline $\mathrm{C}$ & 2.12 & 35.10 \\
\hline $\mathrm{D}$ & 1.58 & 25.88 \\
\hline
\end{tabular}

${ }^{a} \mathrm{~N}$ content obtained from elemental analysis. ${ }^{\mathrm{b}} \mathrm{BCVC}$ content calculated from $\mathrm{N}$ content.

\section{RESULTS AND DISCUSSION}

\section{Polymerization}

Copolymerizations of IBMA and BCVC were carried out with various molar feed ratios using AIBN as a radical initiator. The results are summarized in Table I. BCVC was readily copolymerized with IBMA in high yield in the presence of a radical initiator (Figure 1). Analysis of copolymer composition by NMR is difficult because aliphatic protons of IBMA and BCVC are shown in the same regions. Copolymer composition was calculated on the basis of the $\mathrm{N}$ content in the copolymer obtained from elemental analysis (Table II). The mole fractions of $\mathrm{BCVC}$ in the copolymers were smaller than those in the feed.

\section{Deprotection Mechanism}

The acid-catalyzed cleavage of protecting groups was studied by FT-IR and TGA. A solution of poly(IBMAco-BCVC) (polymer B) containing $7 \mathrm{wt} \%$ TPSHFA was spun on a $\mathrm{NaCl}$ plate and baked at $120^{\circ} \mathrm{C}$ for $2 \mathrm{~min}$. The 


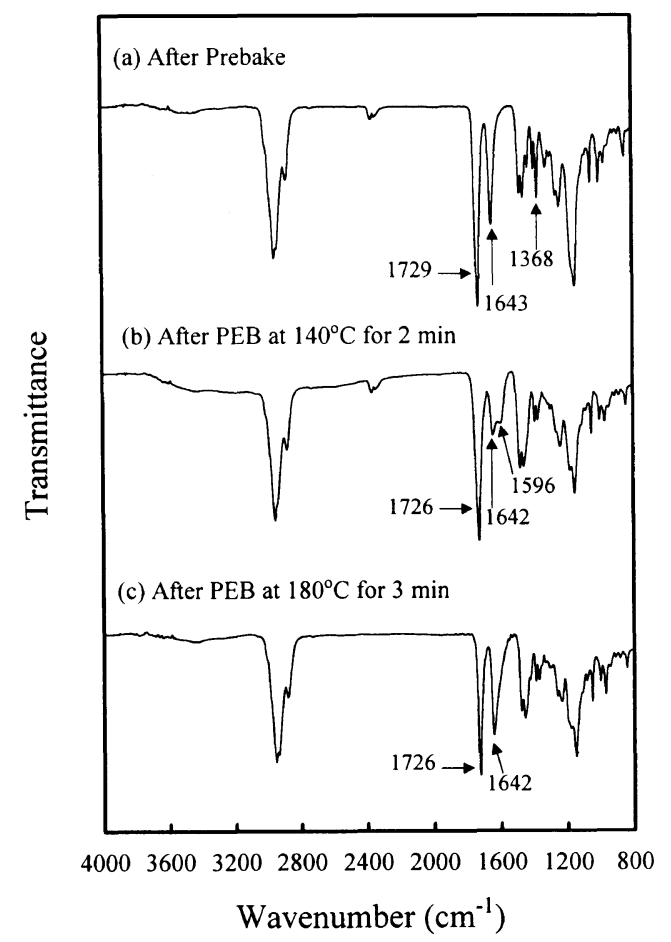

Figure 2. Infrared spectral change of poly $\left(\mathrm{IBMA}_{0.59^{-}}-\left(0-\mathrm{BCVC}_{0.41}\right)\right.$ before (a) and after (b), (c) acidolysis (b, PEB at $140 \mathrm{C}$ for $2 \mathrm{~min}^{-1}$; c. PEB at $180 \mathrm{C}$ for $3 \mathrm{~min}^{-1}$ ).

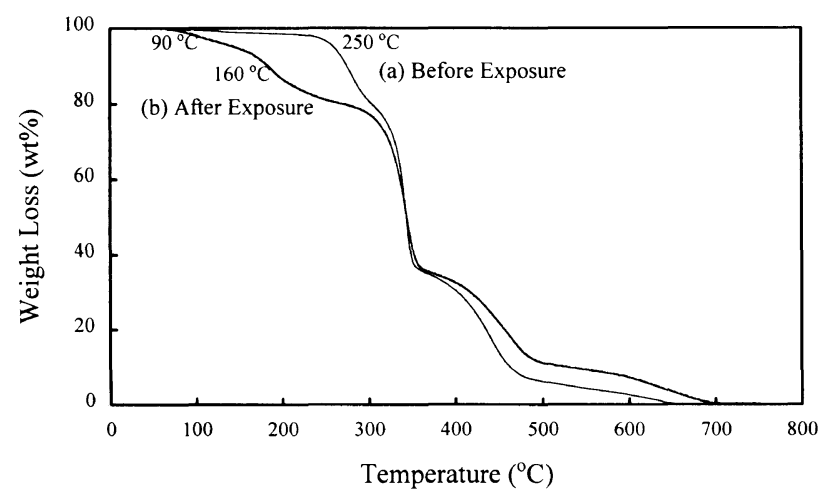

Figure 3. Comparison of TGA thermograms of (a) polymer (poly $\left(\mathrm{IBMA}_{0.59}-\mathrm{c} o-\mathrm{BCVC}_{0.41}\right)$ ) and (b) resist containing $7 \mathrm{wt} \%$ of TPSFHA after deep UV exposure.

FT-IR spectrum of the film was recorded as shown in Figure 2a. The film was exposed to deep-UV light $(220-260 \mathrm{~nm})$ with a dose of $40 \mathrm{~mJ} \mathrm{~cm}^{-2}$ and baked (PEB) at $140^{\circ} \mathrm{C}$ (Figure 2b) and $180^{\circ} \mathrm{C}$ (Figure 2c) for $2 \min ^{-1}$, respectively. In Figure $2 \mathrm{a}$, the absorption bands at $1729 \mathrm{~cm}^{-1}, 1643 \mathrm{~cm}^{-1}$, and $1368 \mathrm{~cm}^{-1}$ correspond to ester carbonyl of IBMA and BCVC, amide carbonyl of $\mathrm{BCVC}$, and $t$-butyl groups of BCVC, respectively. Figure $2 b$ shows that the cleavage reaction resulted in disappearance of the $t$-butyl group and formation of the carboxylic acid group on the polymer. The $\mathrm{C}-\mathrm{H}$ band of the $t$-butyl group at $1368 \mathrm{~cm}^{-1}$ shrinks after cleavage with formation of a new broad band corresponding to the carboxylic acid $\mathrm{O}-\mathrm{H}$ band at about $3400 \mathrm{~cm}^{-1}$. The absorption band of the amide carbonyl group of BCVC unit in the copolymer is split into two. The amide carbonyl band of the 1-vinyl-2-caprolactam-3-carboxylic acid (VCCA) is shown at $1596 \mathrm{~cm}^{-1}$ and the other band

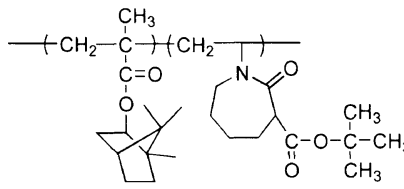

Poly(IBMA-co-BCVC)
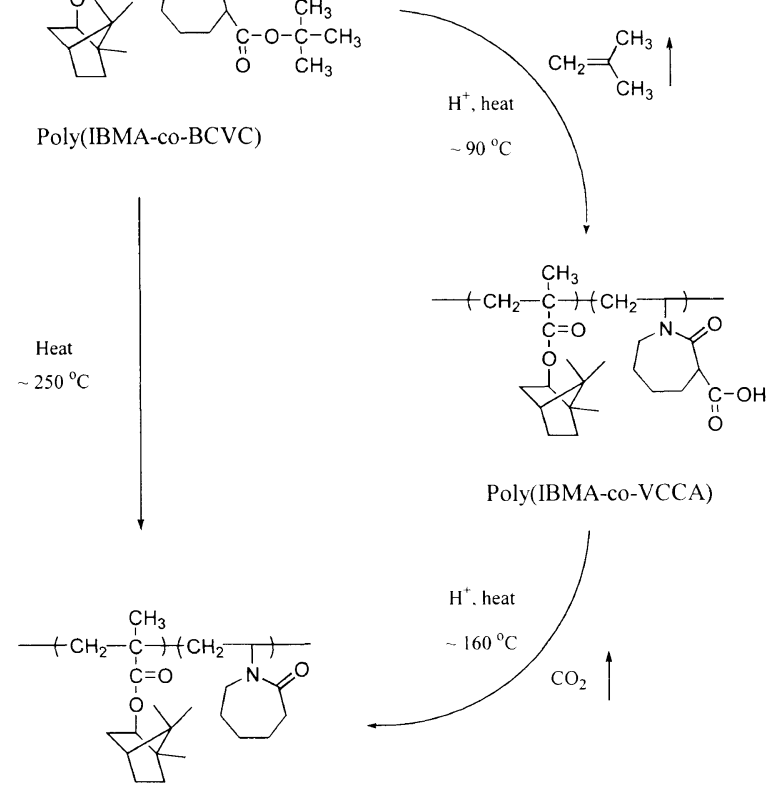

Poly(IBMA-co-VCCA)

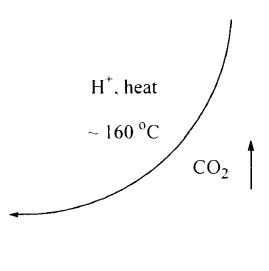

Poly(IBMA-co-VC)

Figure 4. Deprotection mechanism of poly(IBMA-co-BCVC).

at $1642 \mathrm{~cm}^{-1}$ is characteristic of amide carbonyl of 1 vinyl-2-caprolactam (VC). Figure 2c shows that cleavage of $t$-butyl groups and decarboxylation of BCVC unit of poly(IBMA-co-BCVC) occurs completely and poly(IBMA-co-BCVC) is converted to poly(IBMA-coVC). The carbonyl band at $1726 \mathrm{~cm}^{-1}$ is the ester carbonyl band in IBMA unit. The carboxylic $\mathrm{OH}$ band at around $3400 \mathrm{~cm}^{-1}$ disappeared. Thus, the isobornyl group in IBMA unit seems to remain. The acid-catalyzed cleavage of pendant $t$-butoxycarbonyl ( $t$-BOC) groups in the exposed area resulted in a large change of polarity of the polymer from aqueous base insoluble poly(IBMAco-BCVC) to soluble poly(IBMA-co-VCCA) or poly(IBMA-co-VC).

Figure 3 shows TGA curves of the resist before (a) and after (b) exposure at $40 \mathrm{~mJ} \mathrm{~cm}^{-2}$. Poly(IBMA-co$\mathrm{BCVC}$ ) (polymer B) was found to be stable up to $250^{\circ} \mathrm{C}$. At that temperature, a rapid weight loss took place due to evolution of isobutene and carbon dioxide resulting from spontaneous thermolysis of the $t$-butoxycarbonyl groups. Poly(IBMA-co-BCVC) was converted to poly(IBMA-co-VC) as shown in Figure 4. In the presence of photo-generated acid, stepwise deprotection ${ }^{10.11}$ of $t$-BOC groups occurred. The cleavage of the $t$-butyl groups of poly(IBMA-co-BCVC) is found to begin around $90^{\circ} \mathrm{C}$, and then the carbon dioxide was evolved at about $160^{\circ} \mathrm{C}$ subsequently. Poly(IBMA-co-BCVC) was converted to poly(IBMA-co-VCCA) and finally to poly(IBMA-co-VC).

\section{Diffusion Length of Photo-Generated Acid}

The acid generated from the PAG diffuses in the resists during PEB and encounters and deprotects $t$-BOC protecting groups as a catalyst. After the acid takes part in the reaction, it diffuses again in the resists. The photo-generated acid can diffuse into the unexposed area 


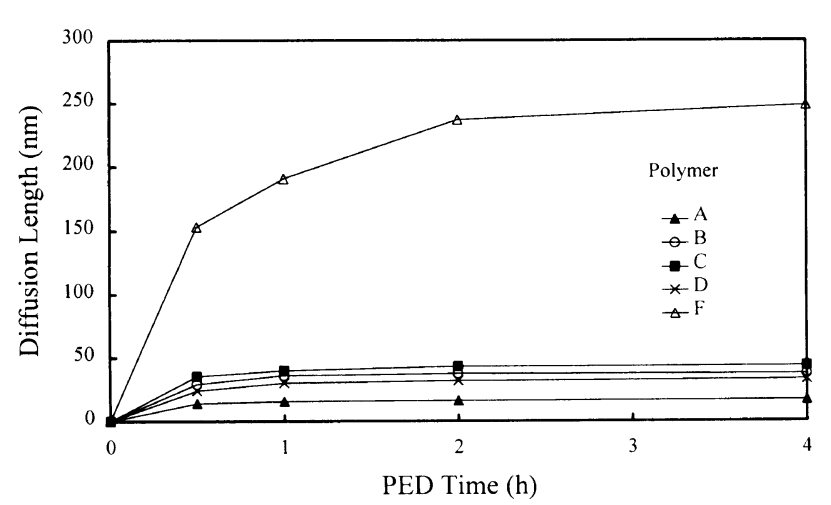

Figure 5. Relationship between PED time and the diffusion length of photo-generated acid.

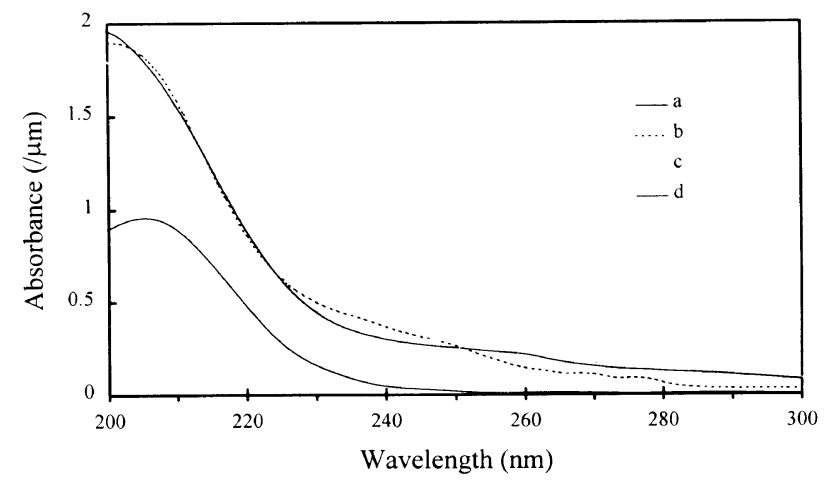

Figure 6. UV absorption spectra of poly( $\mathrm{IBMA}_{0.59}$-co- $\left.\mathrm{BCVC}_{0.41}\right)$ without (a) and with (b) $7 \mathrm{wt} \%$ TPSHFA after exposure (c) and PEB (d).

during PED which causes linewidth slimming. ${ }^{1,2}$ The diffusion length of the acid in the resist film during PED was measured to investigate the behavior of the acid in the presence of a basic matrix polymer. The regions penetrated by the acid become soluble in the developer, thus the diffusion length could be determined from the depth difference between exposed and unexposed regions. ${ }^{20.21}$ Diffusion length was plotted as a function of PED time for baking temperature of $110^{\circ} \mathrm{C}$, as shown in Figure 5. The diffusion length in $\operatorname{poly}(p$-hydroxystyrene $_{0.62}$-co- $t$-butyl acrylate $_{0.38}$ ) (poly(HOST H.62-co- $_{0.6}$ $\mathrm{TBA}_{0.38}$ )) (polymer $\mathrm{F}$ ) sharply increased with PED time. In contrast, the diffusion lengths in the copolymers which contain basic BCVC increased slightly with PED time and became almost constant for PED times longer than $1 \mathrm{~h}$. Comparing diffusion lengths, BCVC exhibited a diffusion suppression effect. The diffusion lengths vary with the content of $\mathrm{BCVC}$. For the polymers of large $\mathrm{BCVC}$ fractions (polymers $\mathrm{A}, \mathrm{B}$, and $\mathrm{C}$ ), as expected, the more the $\mathrm{BCVC}$ fraction, the shorter the diffusion length becomes. These results show incorporation of the basic BCVC in the matrix polymer could trap acid and control the acid diffusion.

However, for polymers of the small BCVC fractions (polymers $\mathrm{C}$ and $\mathrm{D}$ ), the diffusion length increases with the BCVC fraction. There is another factor besides the diffusion suppression effect by BCVC. This is the solubility of deprotected polymers in the developer. $t$-BOC groups in BCVC are very easily deprotected by photogenerated acid to become soluble in the developer. Isobornyl groups in IBMA inhibit dissolution. Therefore, the solubility of deprotected polymer increases with the 698
Table III. UV absorbance of polymers

\begin{tabular}{ccc} 
& \multicolumn{2}{c}{ UV absorbance at $248 \mathrm{~nm} / \mu \mathrm{m}^{-1}$} \\
\hline Polymer & Without PAG & With $7 \mathrm{wt} \%$ TPSHFA \\
\hline A & 0.034 & 0.303 \\
B & 0.025 & 0.285 \\
C & 0.019 & 0.260 \\
D & 0.014 & 0.239 \\
\hline
\end{tabular}

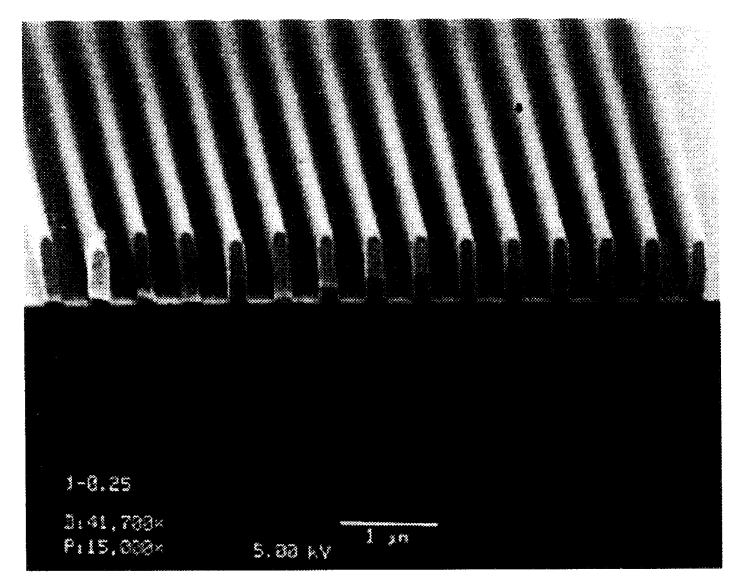

Figure 7. Scanning electron micrograph of $0.25 \mu \mathrm{m} \mathrm{L} / \mathrm{S}$ patterns formed with poly( IBMA $_{0.59}-$ co- $\left.^{-} \mathrm{BCVC}_{0.41}\right)$-based resist at $40 \mathrm{~mJ} \mathrm{~cm}^{-2}$ (PED time, $2 \mathrm{~h}$ ).

BCVC fraction. For polymers of the small BCVC fractions, only highly deprotected polymers can be dissolved in the developer.

\section{UV Absorption Characteristics}

Poly(IBMA-co-BCVC) (polymer B) film displays excellent transparency at $248 \mathrm{~nm}$ (Figure 6a). The major contributor to the absorption of the photoresist at this wavelength is the PAG (Figure 6b). On irradiation and subsequent PEB, the absorption coefficient does not change much at $248 \mathrm{~nm}$ (Figure 6c). The absorbance of the polymer at $248 \mathrm{~nm}$ in the solid state was determined to be $0.025 \mu \mathrm{m}^{-1}$. This is much lower than the absorbance of poly(vinyl phenol)-based resist polymers (Table III). When the IBMA-rich polymer, polymer D, was used as a matrix polymer, the resist pattern was often peeled off the silicon substrate due to poor adhesion. These resist films were brittle because they had alicyclic units dominantly. However, the BCVC-rich polymer, polymer $\mathrm{B}$, gave good adhesion to the silicon substrate.

\section{Lithographic Performance}

In chemically amplified resist systems, delay between exposure and PEB often affects the sensitivity and the resolution. The PED effect was examined on the poly(IBMA-co-BCVC) resist system which contains BCVC as a basic unit. The basic BCVC unit do not only improve the delay stability considerably but also act an acid scavenger especially for long range diffusion of acid molecules to cause linewidth variations. This resist shows a good sensitivity in spite of high concentration of the basic unit because BCVC has a low basicity ${ }^{5,7.8}$ as compared with organic base additives (e.g., 1-methyl-2pyrrolidinone) which have been used in the dispersed 
Table IV. Relative etch rate

\begin{tabular}{|c|c|}
\hline Materials & Relative etch rate \\
\hline Novolac resist & 1.0 \\
\hline Poly(HOST $\left.{ }_{0.62}-c o-\mathrm{TBA}_{0.38}\right)$ & 1.1 \\
\hline $\begin{array}{c}\text { Poly(IBMA } A_{\left.0.59^{-c o}-\mathrm{BCVC}_{0.41}\right)} \\
(\text { Polymer B) }\end{array}$ & 1.2 \\
\hline
\end{tabular}

system. The scanning electron micrograph of $0.25 \mu \mathrm{m}$ patterns formed with poly $\left(\mathrm{IBMA}_{0.59}-\mathrm{co}-\mathrm{BCVC}_{0.41}\right)$ (Polymer C) at $40 \mathrm{~mJ} \mathrm{~cm}^{-2}$ after $2 \mathrm{~h}$ delay is shown in Figure 7. The pattern profile is not deformed and $T$-top is not observed.

\section{Reactive Ion Etch}

The etch rates of poly(IBMA-co-BCVC)-based resists and novolac resist were investigated. Etch rates were obtained by measuring the thickness of polymer films spin-coated on silicon substrates before and after reactive ion etching. Note that under $\mathrm{CHF}_{3}$ plasma, poly(IBMAco-BCVC) has etch resistance comparable to the novolac resist (Table IV).

\section{CONCLUSION}

Copolymers of IBMA and BCVC with various feed ratios were synthesized as matrix polymers in CARs to improve PED stability. The copolymers containing basic monomer units reduced the diffusion length of acid dramatically and prevented $T$-top formation. Thus we have established a new simple method to control the diffusion length of acid during PED and reduce $T$-top formation, which are serious problems in CARs.

\section{REFERENCES}

1. R. D. Allen, W. E. Conley, and R. R. Kunz, in "Handbook of
Microlithography, Micromachining, and Microfabrication, " Vol. 1, P. Rai-Choudhury, Ed., SPIE Optical Engineering Press, Washington, 1997, Chapter 4, p 321.

2. H. Ito, Solid State Technol., 164 (July 1996).

3. S. A. McDonald, N. J. Cleeak, H. R. Wendt, C. G .Willson, C. D. Snyder, C. J. Knors, N. B. Deyoe, J. G. Maltables, J. R. Morrow, A. E. McGuire, and S. J. Holmes, Proc. SPIE, 1446, 2 (1991).

4. O. Nalamsu, M. Cheng, A. G. Timko, V. Pol, E. Reichmanis, and L. F. Thompson, J. Photopolym. Sci. Technol., 4, 299 (1991).

5. H. Ito, G. Breyta, D. Hofer, R. Sooriyakumaran, K. A. Petrillo, and D. J. Seeger, J. Photopolym. Sci. Technol., 7, 433 (1994).

6. W.-S. Huang, R. Kwong, A. Katnani, and M. Khojasteh, Proc. SPIE, 2195, 37 (1994).

7. C. Mertesdorf, N. Munzel, H. Holzwarth, P. Falcigno, H. Schacht, O. Rohde, R. Schulz, S. G. Slater, D. Fey, O. Nalamasu, A. Timko, and T. Neenan, Proc. SPIE, 2438, 84 (1995).

8. H. Roschert, K. J. Przybilla, W. Spiess, H. Wingenroth, and G. Pawlowski, Proc. SPIE, 1672, 33 (1993).

9. Y. Kawai, A. Otaka, A. Tanaka, and T. Matsuda, Jpn. Appl. Phys., 33, 7023 (1994).

10. J.-B. Kim, M.-H. Jung, and K.-H. Chang, Polym. Bulletin, 38 . 241 (1997).

11. J.-B. Kim, M.-H. Jung, J.-H. Cheong, and J.-Y. Kim, J. Photopolym. Sci. Technol., 10, 493 (1997).

12. J.-B. Kim, J.-H. Choi, Y.-G. Kwon, M.-H. Jung, and K.-H Chang, Polymer., 40, 1087, (1998).

13. Y. Kaimoto, K. Nozaki, S. Takechi, and N. Abe, Proc. SPIE, 1672, 66 (1992).

14. S. Takechi, M. Takahashi, A. Kotachi, K. Nozaki, E. Yano, and I. Hanyu, J. Photopolym. Sci. Technol., 9, 475 (1996).

15. N. Shida, T. Ushirogouchi, K. Asakawa, and M. Nagase, $J$. Photopolym. Sci. Technol., 9, 457 (1996).

16. R. D. Allen, G. M. Wallraff, R. A. Dipietro, D. C. Hofer, and R. R. Kunz, Proc. SPIE, 2438, 474 (1995).

17. K. Nakano, K. Maeda, S. Iwasa, J. Ogura, and E. Hasegawa, Proc. SPIE, 2195, 195 (1994).

18. K. Maeda, K. Nakano, T. Ohfuji, and E. Hasegawa, Proc. SPIE, 2724, 377 (1996).

19. J. L. Dekar and N. P. Hacker, J. Am. Chem. Soc., 112, 6004 (1990).

20. K. Asakawa, T. Ushirogouchi, and M. Nakase, Proc. SPIE, 2438, 563 (1995)

21. K. Asakawa, J. Photopolym. Sci. Technol., 6, 505 (1993). 